\title{
Body in Medical encounters of Romanian female patients in (S)pain"
}

\author{
Catalina Iliescu Gheorghiu \\ University of Alicante
}

\begin{abstract}
This paper's purpose is to check whether the bodily self-perception factor plays any role in (female) migrants' alleged underuse of health services. Out of the four main reasons identified by scholars, the "cultural specificity" factor is tackled here from an intersectional perspective that envisages gender, migration and totalitarianism. A survey was conducted on twenty Romanian women living in Spain. Two categories were analysed (body as image and body as discourse) to detect perceptions in consultations in Spain as compared to Romania. The assumption that their perceptions varied between the period prior and subsequent to the fall of the dictatorship was contrasted with information provided by a sample of twentyfive Spanish women required to recall medical encounters during and after Franco's dictatorship.

The analysis revealed perceptions of a more relaxed medical relationship for Romanian patients in Spain, hence the possibility that migration (normally stressful) gave them a sense of freedom and empowerment. A comparison would be needed with Romanian women who remained within the borders of the country. In response to the research question (does the bodily self-perception factor play any role in Romanian female

migrants' alleged underuse of Spanish health services?) it seems that it does not, at least not a meaningful role. Respondents' perceptions of body in medical interactions did not change essentially after the fall of totalitarianism, but they did after migration. This might be due to a more complex process of transformation of the self, but also to the evolution of medical relations over the last two decades worldwide, placing the patient (and not the disease) at the centre of health providers' priorities and allowing him/her to participate in the healing process. The intersectional perspective in health communication is original.
\end{abstract}

This study opens a research avenue in health services' underuse by migrants.

\section{Keywords}

Romanian female migrants; medical communication; bodily self-perception; Spanish integration policies; health under totalitarianism

\section{Background}

Global human mobility (243 million people on the move, representing 3.3\% of the world population) is constantly changing its profile. Shifting patterns include new migration routes, as well as feminization and regionalization of migration. According to the UCL- Lancet Commission on Migration and Health (Abubakar et al., 2018), increases in the migration of women could be due in part to shifts in gender, social, and migration norms, and in other part by remittances they receive, which create greater opportunity for women to migrate. Adolescent girls also migrate for work, driven by financial incentives and hopes for greater freedom and empowerment. Romania is one of the European countries with the greatest number of citizens living abroad, of whom 687733 live in Spain, aged between 20 and 44. They bring with them human capital (knowledge, habits, social and personality attributes, materialized in the ability to perform labour so as to produce economic value) and health capital (an advantage in the labour market and a trigger for their decision to move). More than half of them are women who, under crisis conditions, provide the main support of their families. Employed in housework or caring for children and the aged, they ensure the continuity of the migration project if men attempt a return plan. Due to the social constraints that closely mark medical encounters submitted to the

\footnotetext{
* Iliescu-Gheorghiu, C. (2020), "Body in medical encounters of Romanian female patients in (S)pain", International Journal of Migration, Health and Social Care, Vol. 16 No. 4, pp. 443458. https://doi.org/10.1108/IJMHSC-03-2019-0034
} 
hegemonic biomedical model in different countries and epochs, communication between health providers and patients carries relevant information on the evolution of the conception upon body in general and upon the female migrating body in particular.

A considerable amount of research has been devoted to body and health by social sciences under the light of current migration phenomena but most of it adopts the services', not the users' viewpoint, as Ruiz-Azarola et al. (2018) point out. On the other hand, since the recognition of interpreters as active participants in discursive events in health care contexts at the end of the last century, researchers from Translation Studies have focused, as Hsieh shows (2017: 35), on the interpreters' strategic management of medical encounters, their visibility, role, and performance quality. However, relatively little research has been devoted to the role of the "conversational others" (patients and physicians) in the conceptualization of this (mediated) communicative situation, called by

Wadensjö "pas de trois" and by Mason "triadic exchange".

\section{Aim, hypothesis and preliminary assumptions}

This paper intends to counter for this scantiness by approaching patients' perceptions of their body during medical encounters from an intersectional point of view, bringing the body/gender/migration triad into the health care communicative frame. A group of Romanian migrated women's bodily perception in medical settings both in arrival and departure countries will be explored. The study, intended to check whether the bodily self-perception factor plays any role in (female) migrants' alleged underuse of health services, will inquire about health care exchanges in the past (when physicians were mainly men in both Romania and Spain) and at present, to check the impact (if any) of medical authority on the way these women retrospect themselves to the symbolic value of body as defined by scholars such as Martí Pérez (2008) or Enăchescu (2005), in terms of "body as image" and "body as discourse / action".

According to a tradition rooted in the twentieth century, the body is considered a social (Le Breton 1999/2002) as well as a historical, cultural and symbolic construct (Roca i Girona, 1996: 13) and gender is one of its main variables (Esteban, 2004: 117) together with social class, ethnicity, economic access, etc. Authorities in the field such as Foucault (1979/1992) who analyses policies, control and resistance, or Bourdieu (1979/1988) who delves into the notions of taste, habitus and the relation between body and social class, are fundamental to further developments such as those of Marti (2008), who regards the symbolic value of body as being threefold (actions, gestures and image, the latter including such elements as body care, clothing and modifications). A similar view is held by Enăchescu (2005: 124), who describes the different modalities of body communication as: individual presence through bodiness; body shape, size, colour, and smell; eye contact; the position of the body, gestures, attitudes; reciprocal contact; style, pitch, tone and contents of discourse. Through these categories, which we could classify as (1) body as image, (2) body language, (3) body as discourse, the body communicates with the self and with society. As for the therapeutic act, it encloses, in Enăchescu's opinion, a subjective-emotional load represented by the bodily co-presence of the therapist-patient pair.

This case-study will analyse the categories described by Enăchescu (body as image and body as discourse, or action in Marti`s classification), as they emerge from a survey on twenty Romanian female residents in Spain required to recall medical experiences from the past. The body language category was left for further research since reliable information on kinesics, proxemics and gestures was unlikely to be elicited.

A number of studies have shown that migrants' utilisation of medical services in their host countries is lower than local population's and also lower than their peers' in homecountries. In Spain, this issue was studied by Hernández-Quevedo and Jiménez-Rubio (2009) who explored the existence of inequalities in health and in the access to health services for the immigrant population as compared to that of Spaniards. They conclude that immigrants' self-reported health varies depending on the respondents' nationality, while all immigrants, regardless of their 
nationality, admit having faced barriers of entry to specialized care. The same conclusion is drawn by Urbanos-Garrido (2016) who observed that, in turn, immigrants are more likely to use hospital emergence services. Ruiz-Azarola et al. (2018) found not only worse socio-economic conditions of 36 migrants from Bolivia, Morocco and Romania and their precarious living and working conditions to be the cause of their low access to health services, but also the latter's incapacity to adapt to this population's specific needs. These authors show that access inequity comes from linguistic, cultural, religious barriers and a lack of knowledge about services' norms. They separate potential from real access, differentiating between persuasive (beliefs, attitudes, knowledge) and enabling factors (job security, health coverage). Albeit this interesting view, this paper will adopt the common, fourfold classification of the reasons for this underuse of health services in host countries: a) the healthy migrant effect ${ }^{2}$; b) linguistic and other barriers (e.g. legal); c) working conditions; d) cultural specificities and self-perceptions.

\section{The healthy (labour) migrant effect}

Although the "healthy migrant effect" is a reality (people who migrate are generally healthier than those who do not), as Sundquist (2001: 691) noticed, it tends to "wear off with time".

Forced migration implies losing connections with one's background and adaptation to a new culture. Living in deprived neighbourhoods, being under pressure at work and at home, and exposure to socio-ethnic vulnerability affect migrants' health. Evidence has been presented that apart from material deprivation and sedentarism, labour migration is a factor in long term illnesses. In the same line, Hsieh (2017: 48) claims that since migrants undergo a transition period, often known as culture shock, transition stress often provokes depression, "anxiety or other sequelae that affect their physical health, all as a direct result of their migration experiences and sudden absence of traditional support systems". Ronda-Pérez et al (2014) detected still insufficient research in migrant health and analysed 311 scientific articles in the field, finding that epidemiology prevails as the main theme of the studies performed in Spain on immigrants' health. This might signal a bias in scientific production which exoticizes infectious illnesses and overlook more common ones among migrants (oncological, heart or cerebrovascular disease). Abubakar et al. (2018: 16) confirms that "health and wellbeing of migrant workers is directly related to their working and living conditions and influenced by broader social conditions". Conclusions reached by La Parra, Stornes and Solheim (2017) confirm the healthy migrant hypothesis only among men and women recently migrated to a Western Europe country (after 2003) and show that self-rated health was much worse among longstaying immigrants than among natives, whereas second generation migrant men (but not women - perhaps due to differences in labour profiles) had worse self-rated health than similarly aged natives and new immigrants. Authors consider that low human capital worsens health and wellbeing and wonder whether "past social inclusion policies in Western Europe have failed, progressively transforming immigrants and their descendants into marginalized groups". Scientific bibliography consulted for this analysis reveals information on migrant women, but it lacks specifically focused analyses on female migrants' health or selfperception. Perhaps more dichotomised field data need to be collected.

\section{Linguistic and other barriers}

In Squires's (2017: 4) opinion, migrants may or may not access the healthcare system in their destination country when needed, for two main reasons: the insurance schemes and the language barrier. Regarding the first, even countries with universal coverage, for instance Spain, had stopped providing it to undocumented migrants ${ }^{3}$ in 2012 (using economic crisis and the healthtourism expenditure as an excuse), but restored it in July 2018. Abubakar et al. (2018: 17) states, migrants often do not qualify for medical subsidies and are frequently not covered by the healthcare financing schemes that protect citizens, although the right to the highest attainable health extends to all individuals who migrate, regardless of their circumstances of migration or their legal status ${ }^{4}$. 
Regarding Romanian population living in Spain, the Report by the Institute of Human Rights of the University of Valencia (Mora Castro et al., 2018) recommends: "specific steps should be taken to respond to the special situation of certain groups, such as the Romanian citizens, who, due to administrative barriers or to their social exclusion, might finds themselves at the greatest health risk."

On the other hand, even when migrants know the language of the provider, "healthcare systems in illness descriptors are different enough to affect access to services" (Iliescu, 2007), but when patients have little or no skill in the language of the receiving country "it becomes a major barrier" (Squires, 2017: 3), a reality pointed out in Spanish Public Health services by Velasco, Vinasco and Trilla (2016: 157).

\section{Working conditions}

The Lancet Report (Abubakar et al., 2018: 15) shows that "low wage labour migration is closely linked to globalisation and supply and demand, especially for cheap labour.

Migrant workers in these jobs are often among the most invisible of migrant populations. Not only are they likely to work in informal or even illegal sectors, but they are also less likely to use official resources". To this, we should add individuals with irregular status or who are displaced without a regular residence, who often avoid making themselves known to formal services. After the crisis, the risk of precarious work and unemployment has increased, as well as many migrants' poor labour market positions, which has a direct repercussion on access to health care, as Abubakar et al. (2018: 16) observes: "migrant workers worry about missing work to seek medical care. Especially when workers are paid by piecework or are struggling to pay off debts, missing work is very difficult.

Moreover, if the medical recommendation for injuries or illness is rest and time off, daywage workers are unlikely to heed this advice". This statement is in tune with data revealed by AgudeloSuarez et al. (2009) from a study conducted on 530 Romanian migrants of whom $62,5 \%$ never missed work for health conditions, compared to $37,5 \%$ who sometimes did, although their perceived good health had decreased (84\%) and mental health was lower (78\%) in Spain as compared to Romania (93\%).

\section{Cultural specificities and self-perceptions}

In terms of cultural specificities, barriers have been identified by Vazquez et al. (2016), who suggest "policies should address healthcare services and immigrants" characteristics and other social determinants to avoid health inequalities". In turn, Stronks, Ravelli and Reijneveld (2001) point at "ethnic background to account for a lower utilisation of more specialised health care" by immigrants. In this line, this paper argues that among these "social determinants" and "ethnic background elements" an important role is played by the biomedical model that is inherent to first generation migrants and, due to the historical masculinity of this model, it is especially relevant in the female migrants' case. The traditional "biomedical hegemonic model" (criticized by modern anthropology for its ethnocentric, exclusive and authoritarian views) considers disease a problem exclusively of the body, which is de-personalized, reduced to its biological configuration and individualized as illness carrier. A number of scholars challenged it. Such is the case of the "sensitive communication model" proposed by Geist (1999: 344), based on empathy, empowerment and "learning from one another", since it offers a "significant contribution to our understanding of culture and caring". This model has five layers: ideological, sociological, professional, ethno-cultural and interpersonal and to a certain extent follows the same line as Katan's (1999/2004: 329) “developmental model for cultural sensitivity". Mariano (2008: 308) proposes an "explanatory model", a dialogue provider-patient in which opaque, homogenizing narratives 5 on otherness should be replaced by a wider idea of illness associated with a time, context, experience and social world providing more information on patients, bodies and solutions. Baraldi and Gavioli (2007: 157) show that nowadays, a patient-centered perspective 
invites health care providers to observe illness through the patient's lenses and to treat the patient rather than just the disease. On the other hand, we cannot ignore the force that the "voice of medicine" still has in asserting the primacy of the "medical role performances" based on scientific knowledge and technical competence and of expectations concerning patients' acceptance of medical diagnosis and prescriptions. This is inherited form the age of "golden medicine" (the fifties and the sixties), as Heritage and Maynard (2006) recall,

when interactions between providers and patients were characterized by a doctor-centred perspective. Geist (1999: 345) recognized the predominance among the providers (but also among patients) of the aforementioned "voice of medicine" which envisaged concerns as dualisms (illhealthy; harmful-harmless). Geist proposes a dialectic perspective instead, to help understand health communication in the borderlands of cocultures. To a certain extent, the data provided by my interviewees seem to corroborate the persistence of this "voice of medicine" among practitioners in Romania previous to their migration.

The "medical authority" paradigm has been challenged by models that account for interactions socially constructed on asymmetry (language, gender) such as (1) Lakoff's (1973) "deficit model" explaining how women learn a hesitant language of less impact; (2) Fishman's (1983) "dominance model" explaining how women continually negotiate their powerless position by interrupting less than men or using more open questions (which explains, for instance, my interviewees' preference for female physicians who "communicate better"); (3) Maltz and Borker's (1982) and Coates's (1995) "cultural difference model" which draws a parallel between gender and ethnicity as sufferers of segregation.

The Spanish Statistics National Institute's Report of 6th July 2018 (Instituto Nacional de Estadística, 2018) shows that 52\% Spaniards versus $43 \%$ of EU residents visited physicians in 2017. The 2014 ENSE Report (Spanish Health Ministry) shows that foreign women 10\% more than Spanish women self-evaluated health condition as positive. The conclusion reached by Velasco, Vinasco and Trilla (2016) in their research on several groups of migrants' perceptions of health care in Spain, is that in the case of the surveyed Romanian group, health condition was self-assessed as good or excellent which gives a predicting factor of low demand for Spanish medical services. On the other hand, the management report of the Valencia Regional Ministry of Health (Conselleria de Sanitat Universal i Salut Pública, 2016: 135), shows that in 2015, health assistance given to British residents represented $34,7 \%$ versus $2,8 \%$ Romanian residents, the difference being explained on grounds of migrants' age. But is the "healthy migrant effect" the only reason for this low (patient) profile? This case study will check whether the self-perception and cultural specificities factor plays any role in Romanian female migrants' alleged underuse of Spanish health services.

\section{Methodology and corpus}

I conducted a survey on 20 female informants on the grounds of their alleged bodily experience within the co-culture ${ }^{1}$ to which they belong as women and as migrants. The semi-opened questionnaire I designed comprises 45 questions divided into three blocks referring to careprovider - patient interactions (a) in Romania during the dictatorship (before 1989); (b) after the fall of the communism (1990s) and (c) in Spain, associated to migration (2000s). Respondents were aged between 26 and 77 and had lived in Alicante for a period of between one and 15 years. Their professional life ranged from teaching and nursing to domestic work, and their departure environment was mainly urban (towns of over 70000 inhabitants) from all regions of Romania. Their educational background was of middle or high school, a few were university graduates. As for religion, most were orthodox, three were Neo-Protestant. In terms of social class, they were working or middle class in Romania and broadly speaking working-class in Spain, many with underground employments in domestic work. Some had to ad hoc interpret for relatives in medical encounters, but I obviated this fact as subject for a separate research. Issues covered by the questionnaire were: dressing for consultation, preference between male and female physicians, addressing formulae, tenor, use of technicalities, reluctance to talk about body and symptoms, 
patients' position in encounters, doctors' status, personal feelings during consultation. I also interviewed (voice recorded) some of the respondents who offered additional information on body and its symbolic value. A similar survey (for contrasting purposes only) was completed by 25 Spanish women aged between 54 and 82 who have lived a great part of their lives in urban areas in different parts of Spain (Alicante, Madrid, Valladolid, Valencia) and belong to the uppermiddle classes (teachers, civil servants, nurses, and housewives). Their questionnaire inquired into their relationship with physicians as patients during Franco's dictatorship, the democratic transition and the present day.

The methodology has an intersectional vocation, borrowed from feminist studies, namely from Mc Call's (2005) threefold classification, adopting an intracategorical approach (single-group analysis: migrated Romanian women with an ample age range) and occasionally an intercategorical approach (comparing Spanish and Romanian female patients of a certain age and their perceptions). However, the study is focused on Romanian female residents in Spain and their perceptions on body and medical relations, whereas the information provided by the Spanish informants is intended as support for comparison/corroboration. An analysis of Spanish women's perceptions is beyond the scope of this paper.

Medical science represents a form of control on the human body through technology and the authority of knowledge. This control is conveyed by discourse, which in turn, reveals power patterns in relation to gender, ethnicity (otherness) or educational level. On the other hand, as (Squires, 2017: 3) shows, "legacies of origin country health system strengths and deficiencies will travel with the migrant" since "patients' illness experiences cannot be separated from their culture or language", and their understanding of symptoms is infused, in Hsieh's (2017:48) terms, "with their cultural beliefs, social experiences and folk ideologies". Intersectional research on female body, migration and health in Spain are scarce. Acevedo (2008) delves into the impact of migration on

Maghrebian and Latin American women's health patterns which change as women in the host country are exposed to new risks in the host society and different lifestyles. They are vulnerable because they prioritize finding and holding on to jobs rather than health issues which usually come second (2008: 374). Acevedo's final conclusion is that migration has a negative impact on migrant women who develop nutritional conditions (anaemia, allergies), cardiovascular disorders (due to the drastic dietary changes), gynaecological dysfunctions and nervous complaints related to adaptation stress. There are also changes in the reproductive model, as socio-economic factors make these women more anxious to control fertility. By delving into Romanian female migrants' bodily self-perception, this study expects to find possible reasons for this segment's low utilisation of medical services in Spain.

\section{Analysis and results}

Starting from the assumption that body is a symbol which "embodies" the self's beliefs and communicates them to society, this survey checks Romanian women's perceptions (on issues related to body as image and body as discourse, following Enăchescu or Martí) as they recalled them from health care provider-patient interactions that took place both in Romania and in Spain.

Perceptions of encounters occurred before the fall of the dictatorship were compared to those taking place in its aftermath and to those experienced by the same women as immigrants in Spain. Occasionally, the results were contrasted with Spanish women's perceptions on their own encounters with physicians before and after Franco's regime ended.

\section{Body as image}

Within this category, human scientists usually include: body care (hygiene, hair, skin etc), clothing and modifications (tattoos, piercing etc). As far as the medical encounter is concerned, 
clothing was an essential element because it reveals the degree of formality and respect granted by patients to physicians.

Although medical anthropology categorizes it differently, body exhibition/contact for health purposes will be exceptionally included within the category "body as image" because in this case, neither exhibition nor contact is meant to communicate the self, but rather they are a means of verification, of gathering evidence to support diagnosis in the anamnesis process.

\section{Exhibition/contact}

Regarding body exhibition, Roca (1996: 58) recalls the Francoist dictatorship and its repressive ecclesiastic discourse dividing the human (especially female) body into two categories of organs: those which cannot be exposed publicly since they are "carriers of honour" (mainly reproductive ones) and those which can be revealed, "honest organs" not linked to reproduction. In fact, Spanish informants regard their society as being more reluctant to show the body during a medical check-up (73\% of the informants) than to talk about it (27\%). This rate increases when looking at the Francoist period, since all informants see it as characterized by reluctance to exhibit the body rather than to refer verbally to parts of it, symptoms or physiology. Similarly, $65 \%$ of the Romanian women interviewed considered exhibiting the body more embarrassing than talking about it during the communist dictatorship and the situation remained similar after the fall of the regime. Likewise, $15 \%$ of informants highlighted the fact that in present-day Spain, they are able to express themselves "more freely" and be more relaxed in dialogue with physicians, as compared to Romania, where even nowadays, conversation is "full of barriers". The question posed to interviewees included two variables: professional status (physician versus nurse) and sex (female patients/providers versus male patients/providers). According to informants, $30 \%$ thought that the highest level of reticence was displayed by female patients in interaction with male physicians; $25 \%$ thought it was male patients in dialogue with female physicians, both during the dictatorship and in the post-communist period. Regarding the situation in Spain, it is very interesting to learn that most of the Romanian informants either thought there was no reticence at all $(55 \%)$ or they did not know (35\%). When contrasted with Spanish informants' replies, the following results were obtained: $33 \%$ think there is no such reticence at present, and $16 \%$ still consider male physicians more reluctant to make physical contact with female patients. During Franco's regime, $16 \%$ of the informants thought that all the cross-gender relations at all professional levels (doctors, nurses indistinctly) were characterized by reluctance; $24 \%$ thought male physicians showed reluctance towards female patients, $32 \%$ vice-versa, and another $28 \%$ could not give an answer. During the Transition (a period of adjustments at all levels to democratic principles), $40 \%$ of informants thought reluctance to be higher between female physicians and male patients. This confirms the notion that such professions as medicine, fully occupied by men during the Spanish dictatorship, have since allowed access to women. In fact, some of my informants could not answer about gender-crossed relations because the combination womanphysician/male-nurse simply did not exist in those years. As we can see, the issue of exhibiting body for health purposes is bound to gender.

\section{Clothing}

The other parameter that reveals interesting results is clothing. In totalitarian Romania, except for $30 \%$ of informants who chose to dress "normally", "like for work" when visiting the doctor, $65 \%$ included the term "clean" or "new" in their answers, $25 \%$ of them said: "cleaner than in my daily life". No significant changes were registered with regard to the transition period. Occasionally, when they accompanied relatives to consultation, Romanian immigrant women recall these family members also using "clean and decent" clothes for medical encounters. One informant added that her father always took special care to dress well when going to hospital; another one remembered her mother wearing "new clothes" and a third one mentioned "everyday clothes" but she added "because it was an emergency". Therefore, we see that our informants' relatives, who do not live permanently in Spain, opt for the Romanian social norm in their dressing style, the same as my 
informants used to adopt before migration. Concerning their life in Spain, things changed slightly; only $30 \%$ still mentioned the notion of "cleanliness", while $65 \%$ just wear "normal, decent, daily" clothes, which might show that "cleanliness" no longer claims a verbalization once geographically out of the traditional context. In fact, Spanish informants do not mention the notion of "clean" when referring to the present, but when it comes to the Francoist period, $13.3 \%$ of informants included "cleanliness" in their answers (one of them, aged 82, says "recently bathed"). Of the sample, 28\% talked about "new clothes", "Sunday clothes", or being "better dressed than nowadays". These results, although produced by a small sample, may suggest that the authority physicians used to have in Spain has become a more equal-to-equal relation, not necessarily with democracy, but with the inner evolution of society itself.

The results of the analysis of "body as image" show that in both Romania and Spain, physicians were held in high esteem in the past, especially under totalitarian regimes, therefore, it seems that physician-patient communication patterns related to body as image have to do more with a determinate time in history than with a given culture. In the aftermath of the demise of communism, informants noticed certain changes in status. Nowadays the profession is still recognised but a distinction should be made between social recognition and remuneration. During the dictatorship, physicians' salaries were low (compensated by patients' presents or "envelopes") but their prestige was higher, as Duma and Roșu show (2012), whereas in the present day, apart from psychological and security needs, physicians show a growing need for esteem and social recognition. This is one of the reasons why they migrate, together with the underfunding of the health sector and the lack of facilities. The other reason is remuneration: doctors are $50 \%$ overwaged by other professions. According to $75 \%$ of my interviewees, during the communist regime, physicians vied for first position on the social scale with professors, engineers and lawyers. Today, only $50 \%$ of my interviewees think physicians still lead the social prestige ranking, but now they are upstaged by politicians, bankers and media workers. If we compare these perceptions with the Spanish hierarchy in the views of the 25 surveyed women, 50\% regard physicians at the top together with lawyers, judges, notaries, politicians and engineers.

\section{Body as discourse}

Healthcare encounters provide a clear example of power asymmetry in communication. Until this point, two variables (exhibition and clothing) contingent on the imagistic dimension of body have been discussed. In what follows, this paper will delve into the role the discursive dimension the body plays in asymmetric relations during healthcare provision. For this purpose, two variables will be analysed: "baby talk" (as a patronizing pattern) and taboos (avoidance strategies). Additionally, two other points deemed important to the general results of this field study will be included: gender preference in provider-patient encounters and emotional response as recalled by patients with regard to physicians.

\section{Baby talk}

One of the perils, Cambridge warns (1999: 205) is the use of "baby talk" through which patients lose face $^{6}$ and feel belittled (instead of comfortable) or the use of inappropriate euphemisms (cyst instead of tumour) which save face for the doctor (when giving bad news) but not for the patient when receiving it. To the question about the physician's choice between "heces, deposiciones, caca" [faeces/stool/poop], only 3 out of the 20 Romanian participants chose the option "caca" but assigned it solely to Spanish doctors. No one recalled a single Romanian doctor using this term, which, in the three cases was classified as "quotidian language", whereas "faeces" was clearly ascribed to "scientific" and "stool" semi-scientific language, which Romanian doctors would choose. The Spanish physicians' choice (caca=poop) might be a sign of "baby talk" but might also be a strategy to help decoding, a sign of solidarity. In order to draw a conclusion, a counteranalysis is required. An interpreter mediated dialogue (see Iliescu, 2012a) would reveal doctors' real choice, unconditioned by the inter-linguistic barrier. 
The degree of "solidarity" can be detected, according to Tebble (1999: 186), not only in speakers' syntax and vocation ${ }^{7}$, but also in the use of slang, specialised lexis and taboos.

\section{Taboos}

Taboos is another important variable within the "body as discourse" dimension. Through data collected, I checked whether the traditional taboo referring to parts and functions of the body intervened in my informants' communicative situations and if so, to what extent they modified migrant (and Spanish) women's self-perception. First, informants' awareness of the existence of body taboos is detected, in both home and receiving societies; then, the way they themselves refer (or avoid referring) to their body, illnesses and symptoms in order to detect reticence and if so, in relation to what parts/functions of the body. Both before and after $1989,85 \%$ of informants think Romanian people were reluctant to talk about certain parts/functions of the body, especially genital organs and sexual activity. Their experience as migrants makes them think that Spanish people do not have as much reticence, and that they speak more freely, in a relaxed way about their body and health condition. Only $30 \%$ of informants thought that in Spanish society genital organs and sexual activity were somewhat taboo. Nevertheless, if we compare these results to the survey conducted among Spanish women, the latter acknowledge the (still existing) reluctance to talk about "genital organs and sexual activity" (84\% of informants), while others add "the urinary system" and the "excretory system".

\section{Gender}

The preference for a female physician is a revisited topic in migrant women's narratives. Before 1989 in Romania, except for $10 \%$ of female patients who would have rather gone to a male doctor and $25 \%$ who did not care, the majority (65\%) clearly preferred a woman because they felt "freer and more comfortable"; "better understood"; "more confident", while Spanish women did not seem to have an option during the dictatorship. After 1989, things did not change visibly for Romanian women. As migrants, $10 \%$ of informants preferred male doctors, $30 \%$ had no preferences, and $55 \%$ would choose a woman for the same reasons, plus one: "female physicians communicate better with patients". Spanish women nowadays do not have preferences for health providers of the same or opposite sex. Both Spanish and Romanian informants consider male providers to be more reticent towards female patients than female providers towards male patients.

\section{Emotional response}

When asked whether they felt relaxed, in a situation of inferiority, or intimidated during consultation in Romania and why, our informants mostly chose the third option before and after 1989. While $15 \%$ felt relaxed because of a pre-existing relationship (external to the clinical setting), and $10 \%$ felt inferior due to the use of technical terms, the majority recall a feeling of intimidation. Indeed, when asked (open question) about negative aspects during consultations, Romanian women mentioned "doctors' sense of superiority" among the most frequent aspects: "having to buy gifts for staff", "crowds of people queuing up", "lack of technology and hygiene", "differentiated manners between doctors in rural and urban areas and between the doctors" acquaintances and the man in the street" 8 . When asked about their feelings during consultation, most of the replies focused on the respondents" "worries about the diagnosis", "embarrassment to describe certain symptoms", "embarrassment to ask for further explanation" and "their impression that the doctor was in a hurry or lacked empathy". Of these most frequently enumerated elements, most are related to communication, identified by patients as essential for comfort and wellness. Regarding their feelings towards Spanish health providers, Romanian women did not perceive the same FTAs and felt more empowered. 


\section{Discussion}

The results of the analysis of "body as image" show that in both Romania and Spain, physicians were held in high esteem in the past, especially under totalitarian regimes, therefore, it seems that physician-patient communication patterns related to body as image have to do more with a determinate time in history than with a given culture. In the aftermath of the demise of communism, informants noticed certain changes in status. Nowadays the profession is still recognised but a distinction should be made between social recognition and remuneration. During the dictatorship, physicians' salaries were low (compensated by patients' presents or "envelopes") but their prestige was higher, as Duma and Roșu show (2012), whereas in the present day, apart from psychological and security needs, physicians show a growing need for esteem and social recognition. This is one of the reasons why they migrate, together with the underfunding of the health sector and the lack of facilities. The other reason is remuneration: doctors are $50 \%$ overwaged by other professions. According to $75 \%$ of my interviewees, during the communist regime, physicians vied for first position on the social scale with professors, engineers and lawyers. Today, only $50 \%$ of my interviewees think physicians still lead the social prestige ranking, but now they are upstaged by politicians, bankers and media workers. If we compare these perceptions with the Spanish hierarchy in the views of the 25 surveyed women, $50 \%$ regard physicians at the top together with lawyers, judges, notaries, politicians and engineers.

As showed in Iliescu (2012b: 58) Spain was among the countries that experienced an "unequal and bodily punitive" construction of gender in Roca's (1996: 13) words, through structures such as work division, power, authority, emotional, relational and sexual control exerted by the Church, the institution that monopolized during the postwar years the educational context as well as the ideological, institutional and political power. The paternalistic state, under the pretext of family protection, intervened in the population's reproductive cycles, in their intimate lives, controlling the private territory of body. In totalitarian Romania, as Pasti (2003:101) shows, gender policies improved the traditional model and equalled some differences between sexes, but on the whole, Massino (2004) defined the period as physically oppressive and psychologically terrifying due to appalling living conditions and the Decree 770 which included abortion in the criminal prosecution with penalties of several years in prison, turning obstetricians into guardians with medical instruments under custody and causing havoc among women who saw their body as a weapon used by the regime to spread terror and their sexuality a motive of anxiety and deterioration of the couple (Kligman, 2000: 199).

Regarding "baby talk", the generalized use of interpreters could be the solution to great part of this and other problems which disempower patients, make them lose face, especially women who were treated as children in the past. Healthcare interactions (as social acts, governed by rules and influenced by variables such as speakers' sex, status, roles and distance) share, in Cambridge's opinion (1999: 202), three features: a) the asymmetry of power (one interlocutor has the knowledge); b) the existence of a goal that is external to the encounter (the patient's wellbeing); c) the physician's control of speech turns (which, in other client - provider type exchanges would be unusual), and the patient's frequent unawareness of the rules.

The perception of taboos detected in the case of Romanian and Spanish women regarding each one's society is more or less as expected: both groups see themselves as being still influenced by taboos related to organs and physiological activities owed to strong educational roots. What is striking is the impression held by Romanian women on Spanish society as being less taboo-prone because of their longer experience on the democratic path, which was not confirmed by Spanish women's perceptions and one reason may be the different age average in each group.

As we have seen, "body as image" is closer to power (authority, dictatorship) while "body as discourse" is linked to migration and adaptation/acculturation processes. This emanates from my respondents' answers and was also inherent in questions' formulation. The "body as image" category is based on Martí's "symbolic value" and as such, it can represent (in Foucauldian terms) both control and resistance, hence the proximity to the authoritarian dimension, to how it is used to resist or submit, while "body as discourse" is closer to language which, for Romanian women 
in Spain, is the first and main feature identifying them as migrants, thus bounding discourse/language and body to the migration/integration process.

Two additional variables were gender and emotional response. Regarding gender and medical encounters, the results of this sample seem to show that while Romanian female patients preferred a woman physician during totalitarianism (under communism many women embraced the medical career) and still do so today, Spanish female patients did not have a choice under dictatorship and today they seem not to have preferences, either due to inertia, or due to the fact they do not share the impression of female physicians being better communicators than their male peers.

As far as emotional response is concerned, most of the Romanian informants, recall feeling intimidated by physicians' superiority which persisted until they fled the country, unlike medical encounters in Spain where they feel empowered. This coincides with findings of a survey (Mardare, Furtunescu and Minca, 2018) conducted on 250 Romanian migrants in Spain (70\% women) who pointed at poor health services as the second reason (after low quality of life) for their no-return to the homeland ( $45 \%$ had no intention to return).

\section{Conclusions}

In this study Romanian female migrants' self-perceptions in terms of body and health communication were approached. Out of the four main reasons identified by scholars for (Romanian) migrants' underuse of (Spanish) health services, the "cultural specificity" factor was analysed. The analysis was twofold, delving into aspects related to "body as image" and "body as discourse" (two main categories in Enăchescu or Martí) and focused on the perception on behalf of Romanian women in Spain of the body-gender-migration triangle from a diachronic perspective: during the dictatorship in Romania; in its aftermath; and as immigrants. First, "body as image" category was analysed through two parameters: exhibiting and clothing. In the case of the former, the level of reticence in health encounters was measured (with gender and status doctors versus nurses) variables. Results show that in Romania, both before and after the fall of the dictatorship, reluctance was higher between male physicians with female patients while in Spain the major perception placed female physician with male patient at the top in the past (for its rarity) and no preference at presence. Romanian and Spanish women agreed that a higher degree of embarrassment was felt when exhibiting the body in consultation rather than when talking about it. Finally, $65 \%$ of the Romanian group preferred female physicians in their home country but $10 \%$ fewer did so in Spain, where more migrant women say they do not mind. Regarding clothing for medical encounters (degree of respect towards doctors), a significant change can be noticed after migration: from $65 \%$ of the interviewees who dressed up formally, cleanly and with new garments in Romania, only $30 \%$ still did so in Spain, a percentage closer to the Spanish sample group ( $40 \%$ still using clean, new, formal clothes). The conclusion to be drawn from these data is that Romanian women seem to become more relaxed in Spain in the doctor-patient encounters as far as "body as image" category is concerned.

As for the "body as discourse", two parameters were analysed: the so called "baby talk" and taboos. In the case of the former, no conclusive results have been obtained since the use of childish terms by Spanish physicians (totally opposite to Romanian ones) may be due to presumed decoding problems, not necessarily to a patronizing discursive feature. Regarding taboos, new patterns emerged after migration. Clear change could be noticed, for instance, in Romanian female patients' embarrassment towards anatomy taboos which totally disappeared for $25 \%$ of the interviewees. Since this was noticed both in young and elderly respondents, one conclusion might be that migration gave them a sense of freedom and empowerment.

Two other variables were tackled: gender and emotional response to patient-physician interaction. More than half of the respondents considered female providers to communicate better and preferred them in consultation. As for the feelings elicited by the health care interaction, a vast majority identified a series of FTAs in Romania (both before and after 1989), which they did not seem to detect in their host country. On the other hand, the arrival of new competing jobs - 
politicians, bank managers - that now share the former authority of doctors based on prestige in Romanian society, has also contributed to a change in human relations.

Therefore, in response to the research question whether the bodily self-perception factor plays any role in Romanian female migrants' alleged underuse of Spanish health services, it seems that it does not, at least not a meaningful role.

However, a more general conclusion of this study is that Romanian informants' perceptions of body in medical interactions did not change essentially after the fall of totalitarianism, but they did change after migration. Obviously, this might be due to a more complex process of transformation of the self, but it may also be a result of the evolution of medical relations over the last two decades worldwide (Romania and Spain included), placing the patient (and not the disease) at the centre of health providers' priorities and allowing him/her to participate in the healing process. To complete this analysis a comparison would be needed with Romanian women who remained within the borders of the country.

However, this study has some theoretical and practical implications. In the first place, it tackles three dimensions (body, gender, migration) which affect the complexity of the integration process of migrating minorities in host countries at multiple levels, of which health is paramount. Thus, it opens an avenue for researchers interested in approaching the same issues in the case of other minorities, for instance Roma population, which was not addressed here as it deserves special scholarly attention. On the other hand, this analysis broadens the scope of Interpreting Studies into scarcely explored aspects such as bodily perceptions of migrant women in mediated medical encounters.

From the practitioner's perspective, this study's findings may help improve quality of communication within health care services. Although my results do not seem to confirm reticence based on bodily perceptions as the cause for the underuse of health services on behalf of Romanian female patients living in Spain, my study does show that there is room for improvement in some aspects of these medical encounters. One of them is the mitigation of face threatening acts, better handling of taboos and cultural gaps. A solution would be the generalized use of interpreters. Also, further studies into those elements that make female physicians be perceived as better communicators might be of help in creating communicative environments aimed at all patients' wellbeing.

Finally, as the cultural factor and self-perception does not seem responsible for Romanian women underusing health services, further investigations should look into the other factors (language barrier, working conditions, 'healthy migrant' myth) to explain this reality.

\section{Notes}

[1] Mark Orbe, author of Constructing Co-cultural Theory (1998), suggested that the construction of the identity of a co-cultural group exists within the power structures of a dominant society, in resistance to it. The book explores how people in a co-cultural group communicate with people in the dominant group. Geist (1999: 342) includes gender, ethnicity, religions, sexual orientation, language and wellness within the concept of coculture.

[2] La Parra, Stornes and Solheim (2017) wrote: "the literature on immigrants' health in Europe usually describes that recently arrived immigrants have better health than the host country native population, which could be explained as a labour-related positive health selection. Healthier people are more likely to migrate because they have better options in the labour market. However, once in the host country, the health advantage deteriorates rapidly, [...] faster than among natives."

[3] Doctors of the World Observatory Report (2016) based on data from 9610 patients in European countries, found 4,8\% "personal health reasons" to motivate migration into Spain, only surpassed by the Netherlands $(10,3 \%)$. 
[4] International human rights treaties, most notably the International Covenant on Economic, Social and Cultural Rights, guarantee "the right of everyone to the enjoyment of the highest attainable standard of physical and mental health"; this includes "access to quality essential health-care services and access to safe, effective, quality and affordable essential medicines and vaccines for all" (Abubakar et al., 2018: 18).

[5] Mariano (2008: 3008) defines a narrative as a way of representing and telling events in a coherent, meaningful order together with associated experiences.

[6] Starting from the Gricean politeness conversational maxim, Brown and Levinson (1987) designed a model which defines "face" as the image of the self that an interlocutor wishes to project and preserve. "Positive face" is associated with self-esteem and social regard, whereas "negative face" refers to the right to freedom from imposition. In order to preserve equity in talk, speech acts that might threaten the interlocutor's face (FTA) should be mitigated by minimizing imposition through: indirectness, questions and hedges, impersonal style, passives, that is, by "negative politeness". On the other hand, the impact of FTAs such as criticisms or complaints, can be mitigated by asserting reciprocity, offering praise, help, or by joking and behaving in a familiar way, that is, by "positive politeness".

[7] For instance, $85 \%$ of participants would use "Mr./Mrs. + Dr. + surname" to address physicians in Romania, while in Spain, 35\% would simply translate this formula and $40 \%$ would avoid it by using the polite pronoun "usted". The generalized first name adopted by Spanish providers nowadays strikes Romanian patients as too familiar, since in Romania they would still be addressed as "Mrs. + surname". Eighty per cent of Spanish participants remember "don/doña + first name" as the formula during the Francoist regime and transition.

[8] According to Doboș (2006: 9) until 1997 the centralized health system continued in Romania, totally covered by the state budget and officially free for all (although bribery was generalized). In the 2000s, deficient state financing led to insalubrious facilities, insufficient medicines and technology. Today Romanian users are in general dissatisfied with health services and many miss the soviet centralized model (ibid:12). The European Health Observatory Report (2017) on Romania shows that although most of the population self-evaluate as in good health, life expectancy is 6 years lower than in EU, health system financing is low (GDP health expenditure per person is the lowest in EU), inequity is still high among vulnerable groups and between urban and rural areas. The "Health at a glance" report (2018) finds Romanian men's suicide rate very high.

\section{References}

Abubakar, I. et al. (2018), "The UCL-Lancet Commission on Migration and Health: the health of a world on the move", Lancet Vol. 392, pp. 2606-2654. DOI: 10.1016/S01406736(18)32114-7.

Acevedo Cantero, P. (2008), "La salud, tras la migración, en mujeres latinoamericanas y magrebíes", in Fernández Juárez, G. (Ed.), La diversidad frente al espejo. Salud, interculturalidad y contexto migratorio, Abya Yala, Quito, pp. 373-383.

Agudelo-Suarez, A. et al. (2009), "Proceso migratorio, condiciones laborales y salud en trabajadores inmigrantes en España", Gaceta.Sanitaria, Vol. 23 No. 1, pp. 115-121.

Baraldi, C. and Gavioli, L. (2007), "Dialogue Interpreting as Intercultural Mediation", in Grein, M. and Weigand, E. (Eds.), Dialogue and Culture, John Benjamins,

Amsterdam, NL/Philadelphia, PA, pp. 155-175. DOI: 10.1075/ds.1.12bar.

Bourdieu, P. (1988), La distinción: criterios y bases sociales del gusto, Taurus, Madrid, ES, 1979.

Brown, P. and Levinson, S. C. (1987), Politeness: Some Universals in Language Usage, Cambridge University Press, Cambridge, UK. 
Cambridge, J. (1999), "Information Loss in Bilingual Medical Interviews through an Untrained Interpreter", The Translator, Vol. 5 No. 2, pp. 201-219. DOI: 10.1080/13556509.1999.10799041.

Coates, V. E. (1995), "Measuring constructs accurately: a prerequisite to theory testing", Journal of Psychiatric and Mental Health Nursing, Vol. 2, pp. 287-293. DOI: 10.1111/j.13652850.1995.tb00094.x

Conselleria de Sanitat Universal i Salut Pública (2016), Memoria de gestión de la Conselleria de Sanitat Universal i Salut Pública 2015. Valencia: Generalitat. Conselleria de Sanitat Universal i Salut Pública.

Doboș, C. (2006), Dificultăți de acces la serviciile publice de sănătate în România. Calitatea Vieții, Vol. XVII No. 1-2, pp. 7-24, available at: http://www.revistacalitateavietii.ro/2006/CV-1-2-06/2.pdf. (accessed 19 August 2020)

Duma, O. and Roșu, T. S. (2012), Medical Staff Remuneration. An Ethical Perspective. Romanian Journal of Bioethics, Vol. 10 No. 2, pp. 91-100.

Enăchescu, C. (2005), Fenomenologia trupului. Locul şi semnificaţia Trupului carnal în psihologia persoanei, Paideia, Bucharest, RO.

Esteban, M. L. (2004), Antropología del cuerpo. Género, itinerarios corporales, identidad y cambio, Edicions Bellaterra, Barcelona, ES.

Fishman, P. (1983), "Interaction: the Work Women Do", in Thome, B., Kramarae, Ch. and Henley, N. (Eds.), Language, Gender, and Society, Newbury House, Rowley, MA, pp. 89101.

Foucault, M. (1992), Vigilar y castigar. 20th edition, Siglo XXI, Madrid, ES, 1979.

Geist, P. (1999), "Communicating Health and Understanding in the Borderlands of Cocultures", in Samovar, L. A. and Porter, R. E. (Eds.), Intercultural Communication: A Reader, 9th edition, Wadsworth, Belmont, MA, pp. 341-354.

Heritage, J. and Maynard, D. W. (2006), "Problems and Prospects in the Study of PhysicianPatient Interaction: 30 Years of Research”, Annual Review Sociology Vol. 32, pp. 351-374.

Hernández-Quevedo, C. and Jiménez-Rubio, D. (2009), "A comparison of the health status and health care utilization patterns between foreigners and the national population in Spain: new evidence from the Spanish National Health Survey", Social Science \& Medicine, Vol. 69 No. 3, pp. 370-378. DOI: 10.1016/j.socscimed.2009.05.005. Epub ahead of print 11 June 2009, available at: www.ncbi.nlm.nih.gov/pubmed/19523727 (accessed 19 August 2020).

Hsieh, E. (2017), Conceptualizing Bilingual Health Communication: A Theory-based Approach to Interpreter-mediated Medical Encounters, in: Jacobs, E. A. and Diamond, L. C. (Eds.), Providing Health Care in the Context of Language Barriers. International Perspectives, Multilingual Matters, Bristol, UK, pp. 35-55.

Iliescu Gheorghiu, C. (2007), The Role of Interpreting in Spanish Central and Local Government Integration Policies. The case of the Romanian Population in Alicante. Language and Intercultural Communication, Vol. 7 No. 2, pp. 171-185. DOI: 10.2167/laic273.0

Iliescu Gheorghiu, C. (2012a), "Bodily perception in female ad hoc interpreting: Romanian immigrants in contemporary Spain", Perspectives: Studies in Translatology Vol. 1 No. 15, pp. 163-175. DOI: 10.1080/0907676X.2012.702401.

Iliescu Gheorghiu, C. (2012b), "Identidades corporales de las mujeres rumanas en España: del totalitarismo a la falsa libertad / Body determined Identities of Romanian Women in Spain: From Totalitarism to False Freedom", Revista de Dialectología y Tradiciones Populares Vol. LXVII No. 1, pp. 49-84. DOI: 10.3989/rdtp.2012.03. 
Instituto Nacional de Estadística (2018), Notas de prensa. Available at: https://www.ine.es/prensa/ecv_2017_m.pdf(accessed 19 August 2020).

Katan, D. (2004), Translating Cultures. An Introduction for Translators, Interpreters and Mediators, 2nd. edition, St. Jerome, Manchester, UK, 1999.

Kligman, G. (2000), Politica duplicității: controlul reproducerii în România lui Ceaușescu, M. Dumitrescu (Trans.), Humanitas, Bucharest, RO.

La Parra, D., Stornes, P. and Solheim, E. F. (2017), "Self-rated health and wellbeing among the working-age immigrant population in Western Europe: findings from the European social survey (2014) special module on the social determinants of health", European Journal of Public Health, Vol. 27 No.1, pp. 40-46. DOI: 10.1093/eurpub/ckw221.

Lakoff, R. (1973), “Language and Woman's Place”, Language in Society, Vol. 2 No.1, pp. 4580 .

Le Breton, D. (2002), Sociología del cuerpo, Ediciones Nueva Visión. Buenos Aires, AR.

Mc Call, L. (2005), “The Complexity of Intersectionality”, Signs, Vol. 30 No.3, pp. 1771-1800.

Maltz, D. and Borker, R. (1982), “A Cultural Approach to Male-Female Miscommunication”, in Gumperz, J. (Ed.), Language and Social Identity, Cambridge University Press, Cambridge, UK, pp. 196-216. Available at: https://pdfs.semanticscholar.org/e352/8d78c8d88064ae54c0f75b902ab40b6feb45.pdf (accessed 19 August 2020).

Mardare, I., Furtunescu, F. L., and Minca, D. G. (2018), "Quality of life, health status, stress, life satisfaction and motivation in Romanian diaspora in Spain", Maedica Vol. 13 No. 1, p. 59.

Mariano, L. (2008), "Culturas biomédicas. Textualidades y narrativas opacas en la atención a la población inmigrante”, in Fernández Juárez, G. (Ed.), La diversidad frente al espejo. Salud, interculturalidad y contexto migratorio, Abya Yala, Quito, EC, pp. 305-317, available at: $\mathrm{http} / / / \mathrm{www}$. africafundacion.org/IMG/pdf/diversidad_frente_a_lespejo12_07_definitivo.p df) (accessed 19 August 2020).

Martí Pérez, J. (2008), La cultura del cuerpo, UOC, Barcelona, SP. Massino, J. (2004), "Anonimatul femeii în estetica României Ceaușiste", in Ciupală, A. (Ed.), Despre femei și historia lor în România, Editura Universității, Bucharest, RO, avaliable at: http://ebooks.unibuc.ro/istorie/ciupala/anonimatulfemeii.htm (accessed 19 August 2020).

Mora Castro, A. et al. (2018), Informe jurídico-social sobre la situación de las personas inmigrantes en la Comunidad Valenciana, Instituto de Derechos Humanos (UV), Generalitat Valenciana, Valencia, SP.

Orbe, M. (1998), Constructing Co-cultural Theory. An Explication of Culture, Power, and Communication. Sage, Thousand Oaks, CA.

Pasti, V. (2003), Ultima inegalitate, Polirom, Iași, RO.

Roca i Girona, J. (1996), De la pureza a la maternidad. La construcción del género femenino en la postguerra Española, Ministerio de Educación y Cultura, Madrid, SP, available at: https://www.researchgate.net/publication/289533733_De_la_pureza_a_la_maternidad_la _construccion_del_genero_femenino_en_la_postguerra_espanola (accessed 19 August 2020).

Ronda-Pérez, E. et al (2014), "General Characteristics of the Original Articles Included in the Scoping Review on Health and Immigration in Spain", Revista Española de Salud Pública, Vol. 88 No. 6, pp. 671-674, DOI: 10.4321/S1135-57272014000500001.

Ruiz-Azarola, A. et al. (2018), "La perspectiva de personas migrantes sobre el acceso a la atención sanitaria en el contexto de políticas de austeridad en Andalucía", Gaceta Sanitaria, Epub ahead of print 18 September 2018. Available at: http://www.gacetasanitaria.org/es-la- 
perspectiva-personas-migrantes-sobre-avance-S0213911118302413. (accessed 19 August 2020), DOI: 10.1016/j.gaceta.2018.09.006.

Squires, A. (2017), "The Drivers of Demand for Language Services in Health Care", in Jacobs, E. A. and Diamond, L. C. (Eds.), Providing Health Care in the Context of Language Barriers. International Perspectives, Multilingual Matters, Bristol, pp. 1-19.

Stronks, K., Ravelli, A. C. J. and Reijneveld, S. A. (2001), "Immigrants in the Netherlands: Equal access for equal needs?", J Epidemiol Community Health, Vol. 55, pp. 701-707.

Sundquist, J. (2001), "Migration, equality and access to health care services", $J$ Epidemiol Community Health, Vol. 55, pp. 691-692.

Tebble, H. (1999), “The Tenor of Consultant Physicians: Implications for Medical Interpreting”, The Translator, Vol. 5 No. 2, pp. 179-199.

Urbanos-Garrido, R. (2016), "La desigualdad en el acceso a las prestaciones sanitarias. Propuestas para lograr la equidad", Gaceta Sanitaria, Vol. 30 No. 1, pp. 25-30.

Vazquez, M. L. et al (2016), "Was access to health care easy for immigrants in Spain? The perspectives of health personnel in Catalonia and Andalusia", Health Policy, Vol. 120 No. 4, pp. 396-405. DOI: 10.1016/j.healthpol.2016.01.11.

Velasco, C., Vinasco, A. M. and Trilla, A. (2016), "Percepciones de un grupo de inmigrantes sobre el Sistema Nacional de Salud y sus servicios", Atención Primaria, Vol. 48 No. 3, pp. 149-158. 